\title{
Development and Validation of Vierordt's and Absorbance Ratio Spectrophotometric Methods for Simultaneous Estimation of Aspirin and Omeprazole in Their Binary Mixture
}

\author{
Megha Sharma $^{a, *}$, Anupam Jaiswal ${ }^{b}$, Shalini Shivhareb ${ }^{b}$ Aditi Bapat ${ }^{b}$, Deepak Kumar Jainc \\ a Department of Pharmacy, Gyan Ganga Institute of Technology and Sciences, Jabalpur, (MP) 482003 India \\ b Shri Ram Institute of Technology, Pharmacy, Near ITI Madhotal, Jabalpur, (MP) 482002 India \\ c Medicinal Chemistry Research Laboratory, SLT Institute of Pharmaceutical Sciences, Guru Ghasidas University, \\ Bilaspur, (CG) 495009 India
}

\section{A R T I C L E I N F O}

Received: 04 July 2019

Revised: 24 July 2019

Accepted: 15 September 2019

Available online: 19 September 2019

\section{K E Y W O R D S}

Spectrophotometric methods

Aspirin

Omeprazole

Vierordt's

Q-absorbance equation

\section{A B S T R A C T}

The present study deals with the development and validation of two simple, accurate and precise spectrophotometric methods for estimation of Aspirin (AS) and Omeprazole (OMP) in their binary mixture. The first method was developed using Vierordt's simultaneous equation method. It involves absorbance measurement at 257 and $300 \mathrm{~nm}$ ( $\lambda_{\max }$ of AS and OMP) in methanol. Second method involves the formation of $Q$-absorbance equation using the respective absorptivity values at $284.5 \mathrm{~nm}$ (isoabsorptive point) and $300 \mathrm{~nm}\left(\lambda_{\max }\right.$ of OMP). The drugs obey Beer's Lambert's law in the concentration range of $4-20 \mu \mathrm{g} / \mathrm{mL}$ and $2-10 \mu \mathrm{g} / \mathrm{mL}$ for AS and OMP respectively for both the methods. Limit of quantitation for Vierordt's method for both the drugs was found to be 0.85 $\mu \mathrm{g} / \mathrm{mL}$, whereas for absorbance ratio method it was 0.68 and $0.88 \mu \mathrm{g} / \mathrm{mL}$ for AS and OMP respectively. \% recovery for both the drugs was in the range of 99.78 $100.31 \%$ indicating excellent accuracy for both the methods. The methods were precise, with a relative standard deviation of less than $1.25 \%$ for both drugs. The developed methods were validated according to ICH guidelines and values of accuracy, precision and other statistical analysis were found to be in good accordance with the prescribed values. Thus, both methods can be used for routine monitoring of drugs in industry for the assay of bulk drugs and commercial formulation (Yosprala).

\section{GRA PHICALABSTRACT}

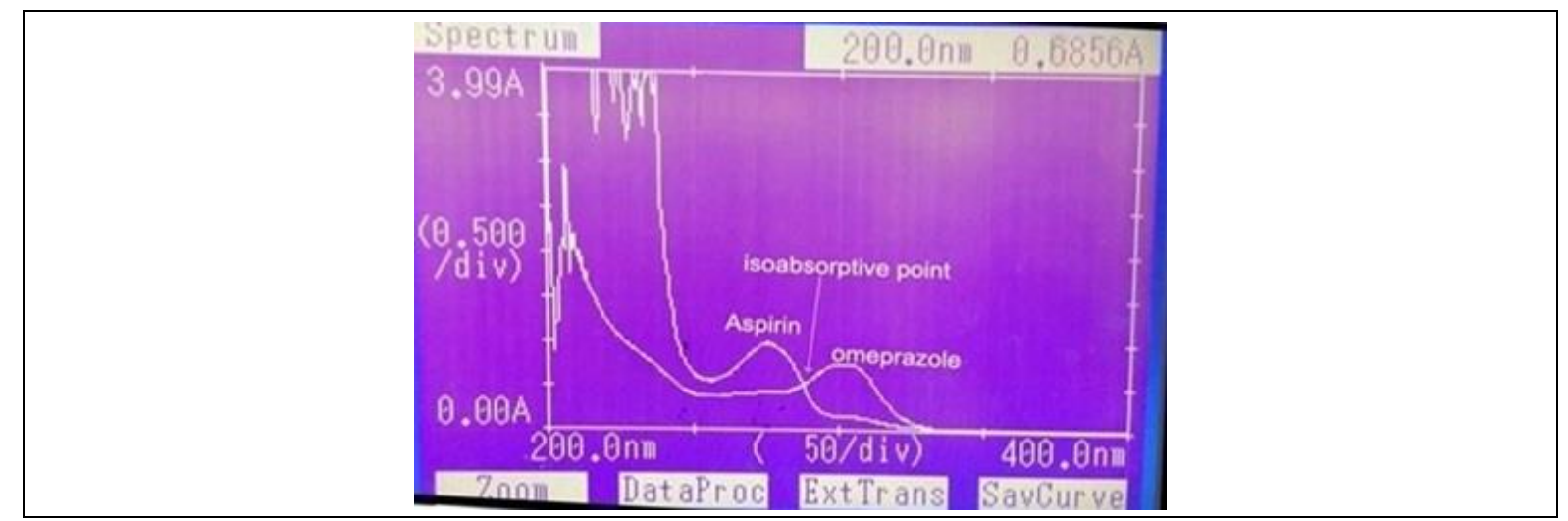

* Corresponding author's E-mail address: meghapharma@rediffmail.com 


\section{Introduction}

Aspirin (AS) (Figure 1a) chemically is 2(acetyloxy)-benzoic acid also called as acetylsalicylic acid and is used for the treatment of pain, fever and inflammation. It is a non-selective cyclooxygenase inhibitor and also having antiplatelet action. AS is used for long-term and helps to prevent heart attacks, strokes and blood clots, in people at high risk [1]. Omeprazole (OMP) (Figure 1b) chemically is 6-methoxy-2-((4methoxy-3, 5-dimethylpyridin-2-yl) methyl sulfinyl)-1H-benzimidazole. OMP is a proton pump inhibitor and is used in the treatment of gastroesophageal reflux and peptic ulcer disease [2]. Recently in 2016 FDA has approved combination of AS and OMP (Yosprala) in two fixed dose regimen. Yosprala is the only therapy designed to sequentially deliver immediate-release OMP for reducing aspirin-associated gastric ulcers and delayed-release AS for secondary prevention of cardiovascular and cerebrovascular events. Combination of contents are available as $81 / 325$ mg delayedrelease AS and $40 \mathrm{mg}$ of immediate-release OMP. The advantage of the combination is that it is more effective than enteric-coated AS in reducing the risk of gastric ulcers with a lower discontinuation rate due to adverse reactions $[3,4]$. Literature survey reveals spectrophotometric [5-7], HPLC [8-10] and HPTLC [11] methods for the estimation of AS alone and in combination with other drugs. Similarly various analytical methods have been reported for estimation of OMP such as HPLC [12,13], HPTLC [14] and LC-MS [15]. OMP in combination with other drugs have also been estimated spectrophotometrically $[16,17]$. No analytical method has yet been reported for the simultaneous determination of AS and OMP in binary mixture. The aim of the research was to explore the possibility of techniques using UV spectrophotometer for simultaneous estimation of AS and OMP in their mixture form. The developed methods were based on simultaneous equation (Vierordt's) and absorption ratio method for simultaneous estimation of both the drugs. Thus, the purpose of the present study was to establish and validate as per International Conference on Harmonization (ICH) guidelines, an accurate, rapid, economical and precise procedure for quantitative analysis of AS and OMP in binary mixture.

\section{Experimental}

\section{Apparatus}

UV-Vis double beam spectrophotometer 1700 (Shimadzu, Japan) with spectral bandwidth of $2 \mathrm{~nm}$ and $10 \mathrm{~mm}$ matched quartz cells was used. Both the drugs were weighed on a Shimadzu $\AA$ analytical balance (AY 220, Shimadzu Corp., Japan).

\section{Materials and methods}

AS and OMP reference substances were provided as gift sample from Torrent Pharmaceuticals Ltd, Ahmedabad India. Analytical grade methanol was purchased from Himedia Laboratory Pvt. Ltd.

\section{Method development}

\section{Standard stock solution}

Standard stock solutions of AS and OMP were prepared by dissolving accurately weighed $10 \mathrm{mg}$ of drugs in $10 \mathrm{ml}$ of methanol separately to get solutions of $1000 \mu \mathrm{g} / \mathrm{mL}$ each. Both were appropriately diluted with methanol to get separate sub-stock solution of $100 \mu \mathrm{g} / \mathrm{mL}$ each.

\section{Determination of $\lambda_{\max }$}

$10 \mu \mathrm{g} / \mathrm{mL}$ standard solutions of both AS and OMP were prepared from respective substock solutions. Both the solutions were scanned in the wavelength region of 200-400 $\mathrm{nm}$ and the $\lambda_{\max }$ was found to be $257 \mathrm{~nm}$ and 
$300 \mathrm{~nm}$ for AS and OMP respectively. They were scanned in the wavelength range of 200-
$400 \mathrm{~nm}$ and the overlain spectrum was obtained (Figure 2).

Figure 1. Chemical structure of (a) Aspirin and (b) Omeprazole<smiles>CC(=O)Oc1ccccc1C(=O)O</smiles>

(a)

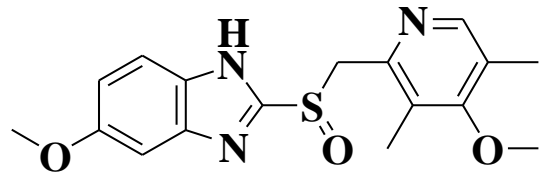

(b)

Figure 2. Overlain spectra of Aspirin and Omeprazole

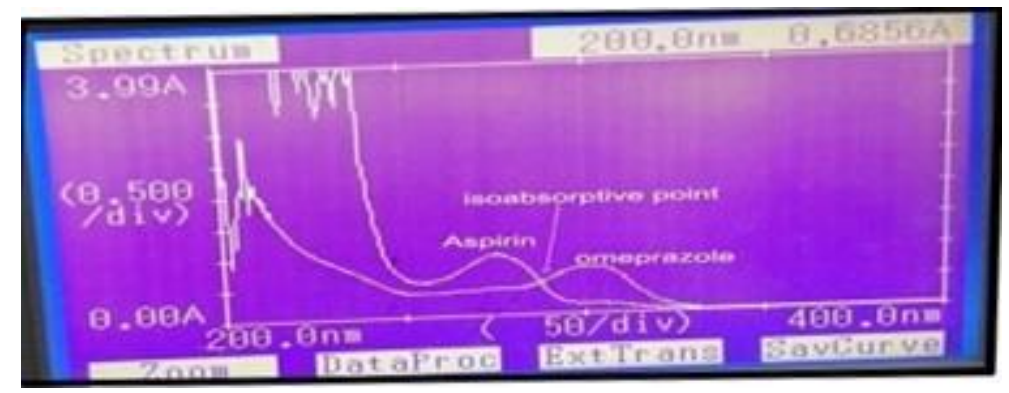

\section{Preparation of calibration curve}

From the standard stock solution of each drug, appropriate aliquots were pipette out into a series of $10 \mathrm{~mL}$ volumetric flasks. The volume was made up to the mark with methanol to get a set of solutions having a concentration range of $4-20 \mu \mathrm{g} / \mathrm{mL}$ and $2-10$ $\mu \mathrm{g} / \mathrm{mL}$ for AS and OMP respectively. Triplicate dilutions of each drug solutions were prepared separately. The prepared working solutions of AS and OMP were scanned at 257 and $300 \mathrm{~nm}$ respectively. All absorbance were recorded and were plotted against the concentrations to obtain their respective calibration curves. The absorptivity coefficients of each drug at both wavelengths were determined.

\section{Preparation of binary mixture}

The binary mixtures of AS and OMP in the ratio of 2:1 as prescribed in Yosprala were prepared from the sub-stock of individual drug by suitable dilution. The dilutions were first vortexes and then used for further analysis.

Method I: Simultaneous equation method
(Vierordt's)

Two wavelengths 257 and $300 \mathrm{~nm}\left(\lambda_{\max }\right.$ of AS and OMP) were selected for the formation of simultaneous equation. The calibration standards in the range of 4-20 $\mu \mathrm{g} / \mathrm{mL}$ for AS and $2-10 \mu \mathrm{g} / \mathrm{mL}$ for OMP were prepared by suitably diluting the sub-stock solutions. The absorptivity coefficients of two drugs at both wavelengths were determined. The concentration of two drugs in the mixture $(2: 1)$ was calculated using equations [18].

$\mathrm{C}_{\text {Aspirin }}=A 2 a y 1 \_A 1 a y 2 / a x 2 a y 1 \_a x 1 a y 2$

$\mathrm{C}_{\text {Omeprazole }}=A 1 a x 2 \_A 2 a x 1 / a \times 2 a y 1 \_a x 1 a y 2$

Where, A1 and A2 are absorbance of mixture at $257 \mathrm{~nm}$ and $300 \mathrm{~nm}$; $\mathrm{ax}_{1}$ and $\mathrm{ax}_{2}$, absorptivities of AS at $257 \mathrm{~nm}$ and $300 \mathrm{~nm}$, respectively; ay 1 and ay 2 absorptivities of OMP at $257 \mathrm{~nm}$ and $300 \mathrm{~nm}$, respectively. $\mathrm{C}_{\text {Aspirin }}$ and $\mathrm{C}_{\text {Omeprazole }}$ are concentration of AS and OMP in mixture. The reported absorptivities are the average of six independent determinations.

Method II: Absorbance ratio method 
Absorbance ratio method utilizes the absorbance ratio at two selected wavelengths, one which is an iso-absorptive point and other being the $\lambda_{\max }$ of one of the two components. From the overlain spectra of both the drugs, wavelengths $284.5 \mathrm{~nm}$ (iso-absorptive point) and $300 \mathrm{~nm}\left(\lambda_{\max }\right.$ of OMP) were selected for the analysis. Five working standard solutions having concentration 4, 8, 12, 16 and $20 \mu \mathrm{g} / \mathrm{mL}$ for AS and 2, 4, 6, 8 and $10 \mu \mathrm{g} / \mathrm{mL}$ for OMP were prepared in methanol and the absorbance at selected wavelengths were measured. The absorptivity coefficients were calculated using calibration curve. Using the following equations concentration of drugs in the mixture can be calculated:

$C_{X}=\left[\left(Q_{M}-Q_{Y}\right) /\left(Q_{X}-Q_{Y}\right)\right] \times A 1 / a_{X 1}$

$C_{Y}=\left[\left(Q_{M}-Q_{X}\right) /\left(Q_{Y}-Q_{X}\right)\right] \times A 1 / a_{y 1}$

Where, A1 is the absorbance of sample at $284.5 \mathrm{~nm}, \mathrm{a}_{\mathrm{x} 1}$ and $\mathrm{a}_{\mathrm{y} 1}$ are absorptivities of AS and OMP at $284.5 \mathrm{~nm}$ and $\mathrm{Q}_{\mathrm{M}}=$ absorbance of sample at $\lambda_{2} /$ Absorbance of sample at $\lambda_{1}$. $\mathrm{Q}_{\mathrm{x}}=$ absorptivity of AS at $300 \mathrm{~nm} /$ absorptivity of AS at $284.5 \mathrm{~nm}$ and $\mathrm{Q}_{\mathrm{Y}}=$ absorptivity of OMP at $300 \mathrm{~nm} /$ absorptivity of OMP at $284.5 \mathrm{~nm}$.

\section{Analysis of laboratory prepared mixtures}

Different ratios of AS and OMP mixtures were prepared and subsequently analyzed. For simultaneous equation method absorbance at 257 and $300 \mathrm{~nm}$ were observed, similarly for absorbance ratio method readings at 284.5 and $300 \mathrm{~nm}$ were taken. From the calculated regression equations, concentrations of both the drugs in the prepared mixtures were calculated.

\section{Methods validation}

Validation of both the methods was carried out in accordance with the
International Conference on Harmonization Q2B guidelines 2005 [19].

\section{Linearity}

Calibration curves were generated with appropriate volumes of working standard solutions for both the methods in the range of $4-20$ and $2-10 \mu \mathrm{g} / \mathrm{mL}$ for AS and OMP respectively. All spectrophotometric determinations were performed in triplicate. The linearity was assessed by the least square regression method.

\section{Limits of detection and quantitation}

Limit of Detection (LOD) is the lowest amount of analyte, which can be detected but not necessarily quantitated as an exact value (Eq. 5). The limit of quantitation (LOQ) is the lowest amount of analyte, which can be quantitatively determined with suitable precision and accuracy (ICH Guideline Q2B, 2005) (Eq. 6).

$\mathrm{LOD}=3.3 \times \sigma / \mathrm{S}$

$\mathrm{LOQ}=10 \times \sigma / \mathrm{S}$

Where $\mathrm{S}$ is the slope of the calibration curve and ' $\sigma$ ' is the standard deviation of the response. The results of LOD and LOQ are shown in Table 1.

\section{Precision and accuracy}

Precision and accuracy both were estimated with standard quality control samples (in addition to calibration standards) prepared in triplicates at different concentration levels covering the entire linearity range. Precision is the degree of repeatability of an analytical method under normal operational conditions and was determined by intra-day precision (repeatability) and inter-day precision (intermediate). 
Table 1. Analytical parameters and linear regression of the methods for determination of Aspirin and Omeprazole

\begin{tabular}{ccccc} 
Parameters & \multicolumn{2}{c}{$\begin{array}{c}\text { Simultaneous equation method } \\
\text { OMP }\end{array}$} & \multicolumn{2}{c}{ Absorbance ratio method } \\
& AS & AS & OMP \\
$\lambda(\mathrm{nm})$ & $257 \mathrm{~nm}$ & $300 \mathrm{~nm}$ & $284.5 \mathrm{~nm}\left(\lambda_{\text {iso }}\right)$ & $300 \mathrm{~nm}\left(\lambda_{\max }\right)$ \\
$\begin{array}{c}\text { Beer's law } \\
\text { range }\end{array}$ & $4-20 \mu \mathrm{g} / \mathrm{mL}$ & $2-10 \mu \mathrm{g} / \mathrm{mL}$ & $4-20 \mu \mathrm{g} / \mathrm{mL}$ & $2-10 \mu \mathrm{g} / \mathrm{mL}$ \\
$\begin{array}{c}\text { Regression } \\
\text { equation }\end{array}$ & $\mathrm{y}=0.008 \mathrm{x}+0.003$ & $\mathrm{y}=0.003 \mathrm{x}-0.004$ & $\mathrm{C}=\left(\mathrm{Q}_{\mathrm{M}}-0.0812 / \mathrm{C}=\left(\mathrm{Q}_{\mathrm{M}}-1.2568 / 1.2568\right.\right.$ \\
& & & $-0.0812) \mathrm{X} \mathrm{A} / 0.082 \quad 0.0812-1.2568) \mathrm{X}$ \\
$\begin{array}{c}\text { Correlation } \\
\text { coefficient }\end{array}$ & \multicolumn{2}{c}{0.996} & 0.990 & \multicolumn{2}{c}{$\mathrm{A} / 0.086$} \\
LOD & $0.32 \mu \mathrm{g} / \mathrm{mL}$ & $0.45 \mu \mathrm{g} / \mathrm{mL}$ & $0.23 \mu \mathrm{g} / \mathrm{mL}$ & - \\
LOQ & $0.85 \mu \mathrm{g} / \mathrm{mL}$ & $0.85 \mu \mathrm{g} / \mathrm{mL}$ & $0.68 \mu \mathrm{g} / \mathrm{mL}$ & $0.37 \mu \mathrm{g} / \mathrm{mL}$ \\
\end{tabular}

Table 2. Data for repeatability and intermediate precision

\begin{tabular}{|c|c|c|c|c|c|c|}
\hline & Simulta & ous equation & ethod & & sorbance ratio & 1ethod \\
\hline Drug & Amt & Intra-day & Inter-day & Amt & Intra-day & Inter-day \\
\hline & $(\mu \mathrm{g} / \mathrm{mL})$ & variation & variation & $(\mu \mathrm{g} / \mathrm{mL})$ & variation & variation \\
\hline & & $(n=6) \%$ & $(n=6) \%$ & & $(n=6) \%$ & $(n=6) \%$ \\
\hline & & $\% \mathrm{RSD}^{* *}$ & $\%$ RSD & & $\% \mathrm{RSD}$ & $\% \mathrm{RSD}$ \\
\hline & & Precision & $\%$ RSD & & $\%$ RSD & $\%$ RSD \\
\hline & & $\pm \mathrm{SD}^{*}$ & Precision \pm SD & & Precision \pm SD & Precision \pm SD \\
\hline AS & 8 & $99.12 \pm 0.24$ & $97.38 \pm 0.11$ & 8 & $99.29 \pm 0.45$ & $99.22 \pm 0.24$ \\
\hline & & 0.25 & 0.18 & & 0.48 & 0.28 \\
\hline & 12 & $98.54 \pm 1.45$ & $99.60 \pm 1.24$ & 12 & $99.20 \pm 0.24$ & $98.84 \pm 0.45$ \\
\hline & & 1.18 & 1.21 & & 0.28 & 0.48 \\
\hline & 16 & $99.32 \pm 0.12$ & $98.85 \pm 0.54$ & 16 & $98.35 \pm 0.18$ & $99.44 \pm 0.45$ \\
\hline & & 0.15 & 0.56 & & 0.19 & 0.47 \\
\hline OMP & 6 & $97.37 \pm 0.35$ & $99.87 \pm 0.24$ & 6 & $98.87 \pm 0.24$ & $97.20 \pm 0.27$ \\
\hline & & 0.35 & 0.29 & & 0.24 & 0.29 \\
\hline & 8 & $98.72 \pm 0.47$ & $99.87 \pm 0.58$ & 8 & $99.45 \pm 0.57$ & $98.84 \pm 1.20$ \\
\hline & & 0.46 & 0.62 & & 0.59 & 1.04 \\
\hline & 10 & $98.74 \pm 0.22$ & $98.18 \pm 0.45$ & 10 & $97.28 \pm 0.74$ & $99.74 \pm 0.27$ \\
\hline & & 0.21 & 0.48 & & 0.74 & 0.29 \\
\hline
\end{tabular}

*Standard deviation

**Relative standard deviation

Precision was evaluated by analyzing sample solutions at three concentrations of AS $(8,12,16 \mu \mathrm{g} / \mathrm{mL})$ and $\operatorname{OMP}(6,8,10 \mu \mathrm{g} / \mathrm{mL})$ respectively. Six replicates were prepared and analysed on the same day for repeatability. Similarly, for intermediate precision same concentrations were freshly prepared and the responses were determined in six replicates. The procedure was performed on three consecutive days and results were expressed in terms of Relative Standard Deviation (\%RSD). Results were reported in Table 2. Accuracy is the percentage of drug recovered by assay on adding a known amount. Recovery 
studies were performed to ascertain the accuracy of the developed method, by standard addition method at three different levels 80, 100 and $120 \%$ (Table 3).

\section{Results and Discussion}

Method development by UVSpectrophotometer is cost effective and time saving as compared to HPLC method of analysis [20]. Thus, for estimation of routine sample of drugs simple, rapid, sensitive and accurate analytical UV methods were utilized which reduces unnecessary tedious sample preparations and use of costly materials. To develop suitable methods of analysis, various solvents were studied. Based on sensitivity of the method and non-toxic behaviour methanol was selected as a solvent for the two suggested methods. Overlain spectra (Figure 2) shows that at $\lambda_{\max }$ of AS $(257 \mathrm{~nm})$ interference of OMP and at $\lambda_{\max }$ of OMP (300 $\mathrm{nm}$ ) interference of AS occurs which suggested development of simultaneous equation method. Similarly AS and OMP shows isoabsorptive point at $284.5 \mathrm{~nm}$ which is different from $\lambda_{\max }$ of both the drugs suggesting estimation by absorbance ratio method. Thus, both the methods provide a simple, convenient, rapid and accurate way to determine AS and OMP simultaneously.

\section{Simultaneous equation method (Vierordt's)}

Sample containing both the analyte (AS and OMP) each of which absorbs at the $\lambda_{\max }$ of the other, then concentration of both can be determined by simultaneous equation method. Two wavelengths selected for the formation of simultaneous equation method are 257 and $300 \mathrm{~nm}$ which are $\lambda_{\max }$ of AS and OMP respectively. The concentrations of each analyte in the sample can be determined using the following set of developed equations:

$\mathrm{C}_{\mathrm{AS}}=\mathrm{A} 2(0.086)-\mathrm{A} 1(0.092) / 0.006106-0.007544$

$\mathrm{C}_{\text {oмP }}=\mathrm{A} 1(0.071)-\mathrm{A} 2(0.082) / 0.006106-0.007544$

Where A1 and A2 are absorbance of sample of mixture of two drugs at selected wavelengths.

\section{Absorbance ratio method}

The present method determines the analyte that follows Beer's Lambert's law depending on the property that, the ratio of absorptivity at any two wavelengths are constant, independent of the concentration or path lengths. This ratio is termed as $Q$-ratio $[21,22]$. Out of the two wavelengths selected one is an iso-absorptive point and another is the wavelength where maximum absorption of any one of the two components appears [23]. From the overlain spectra of the two drugs, it is evident that wavelengths $284.5 \mathrm{~nm}$ is iso-absorptive point and 257 and $300 \mathrm{~nm}$ are $\lambda_{\max }$ of AS and OMP respectively.

Table 3. Results of recovery study

\begin{tabular}{cccccc} 
Level of recovery (\%) & Drug & \multicolumn{2}{c}{$\begin{array}{c}\text { Simultaneous equation method } \\
\end{array}$} & & \multicolumn{2}{c}{ Absorbance ratio method } \\
& & \% Recovery* & \pm SD & \% Recovery* & \pm SD \\
\hline \multirow{2}{*}{100} & AS & 100.12 & 0.021 & 100.31 & 0.054 \\
& OMP & 99.85 & 0.102 & 100.14 & 0.035 \\
& AS & 100.05 & 0.055 & 99.78 & 0.012 \\
& OMP & 100.09 & 0.047 & 100.04 & 0.068 \\
& AS & 100.21 & 0.032 & 100.02 & 0.038 \\
& OMP & 99.89 & 0.201 & 100.11 & 0.187 \\
\hline
\end{tabular}

*Average of six determinations 
Finally $284.5 \mathrm{~nm}\left(\lambda_{\text {iso }}\right)$ and $300 \mathrm{~nm}\left(\lambda_{\max }\right.$ of OMP) were selected for analysis. The absorbance values at selected wavelengths for AS and OMP in the range of $4-20 \mu \mathrm{g} / \mathrm{mL}$ and 2 $10 \mu \mathrm{g} / \mathrm{mL}$ were measured, absorptivity coefficient were determined and average values were taken. The concentrations of each analyte in the sample can be determined using the following set of developed equations:

$$
\begin{aligned}
& C_{A S}=\left(Q_{M}-0.0812 / 1.2568-0.0812\right) \times A / 0.082 \\
& C_{\text {oMP }}=\left(Q_{M}-1.2568 / 0.0812-1.2568\right) \times \text { A } / 0.086
\end{aligned}
$$

Where, $\mathrm{C}_{\mathrm{AS}}$ and $\mathrm{C}_{\mathrm{OMP}}$ are the concentrations of AS and OMP in $\mu \mathrm{g} / \mathrm{mL} ; \mathrm{QM}$ is the absorbance of sample at $\lambda_{284.5}$ / absorbance of sample at $\lambda_{300}$ and $A$ is the absorbance of the sample at $\lambda_{284.5}$. The linearity of the developed methods was evaluated by analyzing different concentrations of standard solutions of AS and OMP in triplicates. For both the developed methods, Beer's Lambert's concentration range was found to be $4-20 \mu \mathrm{g} / \mathrm{mL}$ and $2-10$ $\mu \mathrm{g} / \mathrm{mL}$ for AS and OMP respectively. Good linearity was observed as the values of correlation coefficients were close to unity; the analytical parameters for the constructed equations are given in Table 1.

For simultaneous equation method LOD was found to be 0.32 and $0.45 \mu \mathrm{g} / \mathrm{mL}$ for AS and OMP respectively whereas LOQ for both the drugs was $0.85 \mu \mathrm{g} / \mathrm{mL}$. Result of LOD for absorbance ratio method was found to be 0.23 and $0.37 \mu \mathrm{g} / \mathrm{mL}$ for AS and OMP, similarly values of LOQ were 0.68 and $0.88 \mu \mathrm{g} / \mathrm{mL}$ (Table 1). Thus the results reveal that both the methods are sensitive for determination of drugs studied. Precision for both the methods were reported as \%RSD at different levels; repeatability (intra-day) was analysed for three different concentrations of AS $(8,12,16$ $\mu \mathrm{g} / \mathrm{mL})$ and $\operatorname{OMP}(6,8,10 \mu \mathrm{g} / \mathrm{mL})$ for each in triplicates on the same day and analysis of same concentrations on three consecutive days were repeated for intermediate precision. The results confirmed the precision of the proposed methods as shown in Table 2. For both the drugs the \%RSD values were lower or almost equal to $1 \%$ indicating good precision for simultaneous estimation by both the methods. Accuracy of the developed methods was ascertained by recovery studies and results were reported as \%recovery performed by standard addition technique at three levels (80, 100 and 120\%). Percent recovery for both the drugs was found to be in the range of 99.78 to $100.31 \%$ indicating good accuracy of proposed methods (Table 3 ).

\section{Conclusion}

Two new, simple, sensitive and economical UV spectrophotometric methods were developed for the simultaneous estimation of AS and OMP in their binary mixture. Validation of developed methods was performed according to ICH guidelines. The standard deviation, \%RSD for both the methods are low, reflecting a high degree of precision of the methods. The results of the recovery studies performed show the high degree of accuracy of the proposed methods. Vierordt's and absorbance ratio method has the advantage of being simple, economic, rapid and subsequently not required sophisticated technique, instrument and costly solvents. Thus, the proposed methods can be successfully applied for determination and dissolution testing of AS and OMP in commercial formulation (Yosprala).

\section{Ethics Approval and Consent to Participate}

Not applicable.

\section{Human and Animal Rights}

No Animals/Humans were used for studies that are base of this research.

\section{Consent for Publication}

Not applicable. 


\section{Acknowledgements}

We are grateful to Rewa Siksha Samiti, SRIT Jabalpur for providing us the facility to perform the research work.

\section{Conflict of Interest}

The authors declare no conflict of interest, financial or otherwise.

\section{References}

[1] Sweetman S. C. Martindale: The Complete Drug Reference, Pharmaceutical Press: London, 2005, p 234.

[2] H. Stenhoff, A .Blomqvist, P.O. Lagerstrom, J. Chromatogr. B. Biomed. Sci. Appl., 1999, 734, 191-201.

[3] YOSPRALA (aspirin and omeprazole) Delayed-Release Tablets for Oral Use; Aralez Pharmaceuticals: US Inc. 400 Alexander Park Drive Princeton, NJ, 2016.

[4] D.J. Whellan, J.L. Goldstein, B.L. Cryer, G.M. Eisen, A. Lanas, A.B. Miller, James M. Scheiman, J.G. Fort, Y. Zhang, C. O'Connor, Am. Heart J., 2014, 168, 495-502.

[5] M.D. Game, K.B. Gabhane, D.M. Sakarkar, Indian J. Pharm. Sci, 2010, 72, 825-828.

[6] Z. Kokot, K. Burda, J. Pharm. Biomed. Anal., 1998, 18, 871-875.

[7] P. Mishra, A. Dolly, Indian J. Pharm. Sci., 2006, 68, 365-368.

[8] D.A. Shah, K.K. Bhatt, R.S. Mehta, M.B. Shankar, S.L. Baldania, T.R. Gandhi, Indian J. Pharm. Sci., 2007, 69, 546-549.

[9] E.R. Montgomery, S .Taylor, J .Segretario, E .Engler, D. Sebastian, J. Pharm. Biomed. Anal., 1996, 15, 73-82.

[10] S.L. Yang, L.O. Wilken, C.R. Clark, Drug Del. Ind. Pharm., 1985, 11, 799-814.
[11] P.K. Sinha, M.C. Damle, K.G. Bothara, Eurasian J. Anal. Chem., 2009, 4, 152-160.

[12] M.C. Dubuc, C. Hamel, M.S. Caubet, J.L. Brazier, J. Liq. Chromatogr. Relat. Technol., 2001, 24, 1161-1169.

[13] Z.A. El-Sherif, A.O. Mohamed, M.G. ElBardicy, M.F. El-Tarras, Chem. Pharm. Bull., 2006, 54, 814-818.

[14] P.B. Raval, M. Puranik, S.J. Wadher, P.G. Yeole, Indian J. Pharm. Sci., 2008, 70, 386390.

[15] A. Petsalo, M. Turpeinen, O. Pelkonen, A. Tolonen, J. Chromatogr. A., 2008, 1215, 107-115.

[16] S. Sharma, M.C. Sharma, Arabian J. Chem., 2017, 10, S397-S403

[17] H.M. Lotfy, M.A. Hegazy, S. Mowaka, E.H. Mohamed, Spectrochim Acta A. Mol. Biomol. Spectrosc, 2016, 153, 321-332.

[18] Beckett A.H. Stanlake J.B. Practical Pharmaceutical Chemistry; CBS Publishers and Distributors: New Delhi, 1997, p 123.

[19] H. Ibrahim, A. Boyer, J. Bouajila, F. Couderc, F. Nepveu, ICH Guidelines: Validation of Analytical Procedures: Text and Methodology Q2 (B), J. Chromatogr. B. Analyt. Technol. Biomed. Life Sci., 2005, 857, 59-66.

[20] R. Laxman, A. Acharya, V. Jain, S. Bhardwaj, D. Jain, Int. J. Res. Ayurveda Pharm., 2010, 1, 459-467

[21] K.P. Bhusari, P.B. Khedkar, S. Dhole, V.S. Banode, Indian J. Pharm. Sci., 2009, 71, 505-508.

[22] S.B. Wankheda, S.B. Wadkar, K.C. Raka, S.S. Chitlange, Indian J. Pharm. Sci., 2009,71, 563-567.

[23] D. Ramesh, S. Ramakrishna, Int. J. Pharm. Pharm. Sci., 2010, 2, 215-219.

How to cite this manuscript: Megha Sharma, Anupam Jaiswal, Shalini Shivhare, Aditi Bapat, Deepak Kumar Jain, Development and Validation of Vierordt's and Absorbance Ratio Spectrophotometric Methods for Simultaneous Estimation of Aspirin and Omeprazole in Their Binary Mixture, Adv. J. Chem. A, 2020, 3(3), 328-335. 